\title{
Living Labs as Educational Tool for Ambient Intelligence
}

\author{
Author(s) \\ Robben, Saskia; Kanis, Marije; Kröse, B.J.A.; Veenstra, Mettina \\ Publication date \\ 2012
}

Document Version

Final published version

Published in

Ambient Intelligence

Link to publication

\section{Citation for published version (APA):}

Robben, S., Kanis, M., Kröse, B. J. A., \& Veenstra, M. (2012). Living

Labs as Educational Tool for Ambient Intelligence. In Ambient

Intelligence: Third International Joint Conference, Aml 2012 (Vol.

7683). (Lecture Notes in Computer Scienc). Springer Verlag.

It is not permitted to download or to forward/distribute the text or part of it without the consent of the author(s) and/or copyright holder(s), other than for strictly personal, individual use, unless the work is under an open content license (like Creative Commons).

If you believe that digital publication of certain material infringes any of your rights or (privacy) interests,

please let the Library know, stating your reasons. In case of a legitimate complaint, the Library will make the material inaccessible and/or remove it from the website. Please contact the library:

https://www.amsterdamuas.com/library/contact/questions, or send a letter to: University Library (Library of the University of Amsterdam and Amsterdam University of Applied Sciences), Secretariat, Singel 425, 1012 WP Amsterdam, The Netherlands. You will be contacted as soon as possible. 


\title{
Living Labs as Educational Tool for Ambient Intelligence
}

\author{
Ben Kröse, Mettina Veenstra, Saskia Robben, and Marije Kanis \\ Amsterdam University of Applied Sciences, Duivendrechtsekade 36-38, 1096 AH, \\ Amsterdam, The Netherlands \\ \{B.J.A.Krose, M.Veenstra, S.M.B.Robben, M.Kanis\}@hva.nl
}

\begin{abstract}
The way that innovation is currently done requires a new research methodology that enables co-creation and frequent, iterative evaluation in realworld settings. This paper describes the employment of the living lab methodology that corresponds to this need. Particularly, this paper presents the way that the Amsterdam University of Applies Sciences (HvA) incorporates living labs in its educational program with a particular focus on ambient intelligence. A number of examples are given to illustrate its place in the university's curriculum. Drawing on from this, problems and solutions are highlighted in a 'lessons learned' section.
\end{abstract}

Keywords: Ambient Intelligence, Living Labs, Education, participatory design.

\section{Introduction}

Current societal changes are important external drivers for new innovations in information technology. For example, in The Netherlands 'topsectoren' (innovation spearheads) are driven by grand societal challenges, such as global warming, ageing societies or security.

Also the way that innovation is done, is changing. Traditionally, new products used to be put on the market after a linear sequence of research and development, that was done in research labs and companies. Faster development and production techniques have brought on a new type of design methodology that has an iterative nature: products and services are developed in close collaboration with stakeholders (e.g. end users, distributers and financers) that are continuously tested and redesigned from early on. Furthermore, design is no longer solely focused on the product, but more directed towards the service and the user experience. On top of this, the design cycle should be open: stakeholders should work together.

The new way of innovating requires a new research methodology that enables cocreation, early testing and iterative evaluation in real-world settings. Such a methodology is the 'Living lab' methodology.

In this paper, we will focus on the importance of the living lab methodology for the education of new professionals. We will start describing the living lab concept, the context of our university and show the way of working by describing a number of projects. We will give some guidelines for implementation. 


\section{$2 \quad$ Living Lab Methodology}

The concept of living labs was originally coined by Bill Mitchell at MIT, as an approach that represents a user-centric methodology for sensing, prototyping, validating and refining complex solutions in evolving real life contexts. The first Living Labs that were created from the initial idea happened in the area of smart/future homes. In those settings, real people (visitors) were observed in their usage of emerging technologies in the setting of a real home. In many of the implementations, people stayed in these homes for several days or weeks. New types of ICT, such as video based communication [6] and sensor monitoring [1] were studied. Later on, this concept was extended, in the sense that there was a strong emphasis on co-design, and participation of end-users. In [7] a number of cases have been described in the European context. However, according to Følstad [4], the current body of Living Lab research literature indicates a lack of common understanding of how Living Labs can be used for ICT innovation and development. Moreover, there appear to be only few cases describing how living labs are used in educational settings (such as done at the Amsterdam University of Applied Sciences). We consider a living lab as:

- an environment where partners are jointly involved in Research \& Design

- a setting that exposes users to novel (ICT) solutions

- a (semi) realistic context

- suitable for longterm experiments

- a place for the evaluation of new developments as well as for the discovery of new possibilities

It needs:

- A physical set-up (such as a building or part of the city)

- An (ICT) infrastructure

- Access to end users

- Willingness to collaborate

- Evaluation tools (for doing research 'in the wild')

Two research groups at the Amsterdam University of Applied Sciences ('Digital Life' and 'Interactive Public Spaces') have adopted the living lab methodology in their educational programs, resulting in a living lab on public screens and a health living lab.

\section{Embedding Living Labs in the Educational Program}

The Amsterdam University of Applied Sciences (HvA, Hogeschool van Amsterdam), is focused on higher professional education and consists of seven schools. The school of Design and Communication runs a wide range of creative departments ranging from AMFI (Amsterdam Fashion Institute) to ITCS (Information Technology and Computer Science). These departments offer courses with creativity and innovation as its core elements. 
CREATE-IT Applied Research is the research centre of the school of Design and Communication. At this centre, lecturers, students and researchers conduct practical and applied research on behalf of the creative and ICT industry, in collaboration with universities and other research institutes. The results of the research that is being conducted is aimed to highly benefit the professional field and are also used to help maintain the educational program on the cutting edge.

The research conducted can be called pragmatic, as the research relates to real-life cases and problems in the business segment. The general goals of the research are mainly directed towards the improvement and innovation of the professional practice. The research produced is aimed to be of high quality, and the research structure and methodology are aimed to fulfill all necessary criteria with regard to diligence, reliability, validity, impartiality and independence.

CREATE-IT's Applied Research have jointly set up a course on 'Ambient Interaction' in which students spend six months in research teams. These teams work on applied research projects, together with a (creative) company or institute that has particular real-life research questions. Also a number of students working on their bachelor's thesis were involved in these projects.

For these students we defined projects that were to be carried out in one of our living labs. The expected benefits of the approach were:

- The students collaborate with all stakeholders (end users, technology providers, roll out partners);

- The students are confronted with the entire cycle of user analysis, design, prototyping and user studies;

- Because of the existing infrastructure (ICT, end users) the students can start rapidly.

To offer more insights in our approach, a number of cases are given in the next two sections, in which we describe how students are involved in research in living labs. Then, in section 6 we present our lessons learned.

\section{$4 \quad$ Public Spaces}

In a dynamic context such as a public space, the situation and needs of the public constantly evolve and change over time. In a living lab, system designers and researchers are able to take this changing context into consideration so that systems can evolve simultaneously. BiebBeep is an example of a project that directly derived from using the living lab methodology and has been developed in the public space of a library in Almere, The Netherlands. This library as a living lab environment was used as explorative and educational space for students and has inspired continuous projects in this setting. 


\subsection{BiebBeep}

To meet the demands of current and next-generation users, libraries -such as the one in Almere- nowadays face the challenge of innovating their physical and virtual services and utilizing digital media to provide state-of-the-art, so called Library 2.0 services. Casey [3] describes this Library 2.0 concept as a modernized form of library service whereby the focus lies on user-centered change and participation in the creation of content and community. BiebBeep, a large interactive touchscreen is an interactive screen that has been developed with the aim to augment the information and social function in the public space of a library. Two students from computer science and electrical engineering developed this together with Create-IT and the Novay research centre. BiebBeep displays user-generated and context-relevant content, such as information about local events and book trailers. The system's distinctive feature is that people can add information to the screen themselves, such as tweets and Flickr photos, so that the library and its visitors can inform and connect with each other. For more than a year, the BiebBeep system has been iterated and studied in the library to best meet the demands for its actual use in present and future. Other projects that stemmed from this research have focused on giving further shape to the Library 2.0 of the future, by experimental projects exploring how the library experience can be made more attractive, personal and sociable.

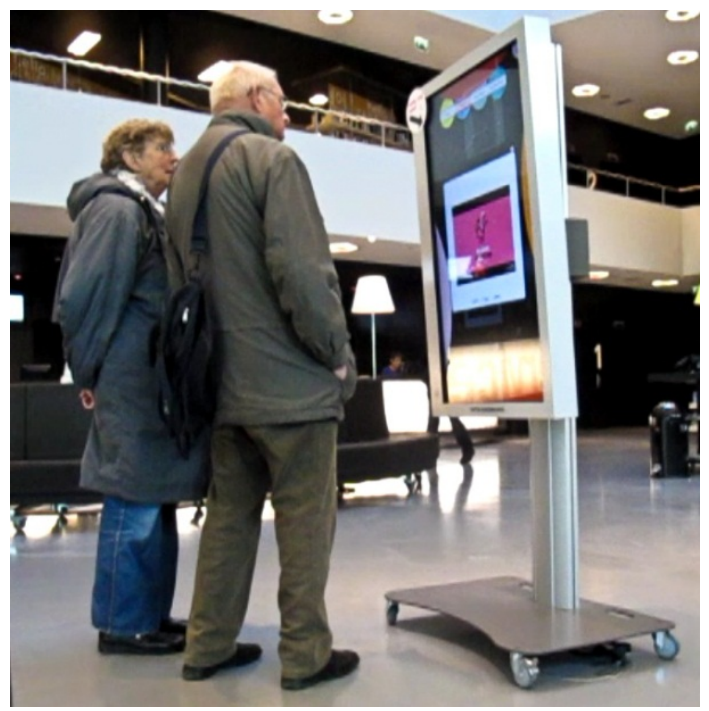

Fig. 1. Interactive touchscreen in the public library of Almere

\section{$5 \quad$ Health-Lab}

Health-Lab, a program in the metropolitan region of Amsterdam, focuses on innovative solutions for enabling people to live longer independently. In Health-lab, 
people from care institutions, research centers, educational institutes and companies work closely together with the end-users to co-create (technical) solutions. The HvA is participating partner in the Health-lab program and uses the program to stimulate innovation in education and research. Within this program, we have set up two 'living lab' locations, where real users can test applications in their daily life so to help designers and developers improve their products.

The first living lab, which was set in motion in 2006, was nursing home Naarderheem, The first projects conducted in this environment were focused on an intramural setting in which patients were monitored during the night. Soon after, a second 'living lab' came about, involving apartments that were built close to the nursing home and eventually equipped as ambient assisted living environments. Two typical projects in which students were involved are described in the next sections.

\subsection{Monitoring ADL in Assisted Living Apartments}

A number of projects conducted in our Living Labs evolve around the monitoring of daily activities in ambient assisted living environments. Engaging the elderly participants and other stakeholders through co-design plays a crucial role in these projects, but also the technical side of employing sensors for examining (deviations in) activity patterns in the home is studied in depth, e.g. [9]. Students were involved in both the technical- as well as the user- oriented studies.

One of the first user-centred studies involved the monitoring of daily activities from the perspective of medical specialists, in which interviews with medical experts and professional caregivers were carried out by two students to make an inventory of their needs for telemonitoring [2]. A second project, Senior-Create IT [5], which was done in collaboration with researchers and four students from the program 'Ambient Interaction', focused on the needs and attitudes of elderly people with regards to monitoring their daily activities with sensors in the home. Following on from this, 25 students from the university's program on Communication and Multimedia Design were given the assignment to develop five iPad applications in groups of five that displays the ambient data in relevant and meaningful way to senior users. In the design of these products, elderly were also actively engaged in the design of these products, in order to contribute to the success and acceptance of such technology. Another student from a Technical Informatics course got then involved in linking the developed iPad applications with the actual systems in the Living Lab environment in Naarderheem, while graduation students in occupational therapy continued with more in-depth studies concerning elderly's attitutes with regards to telemonitoring and also evaluated the developed iPad applications with the elderly users. 


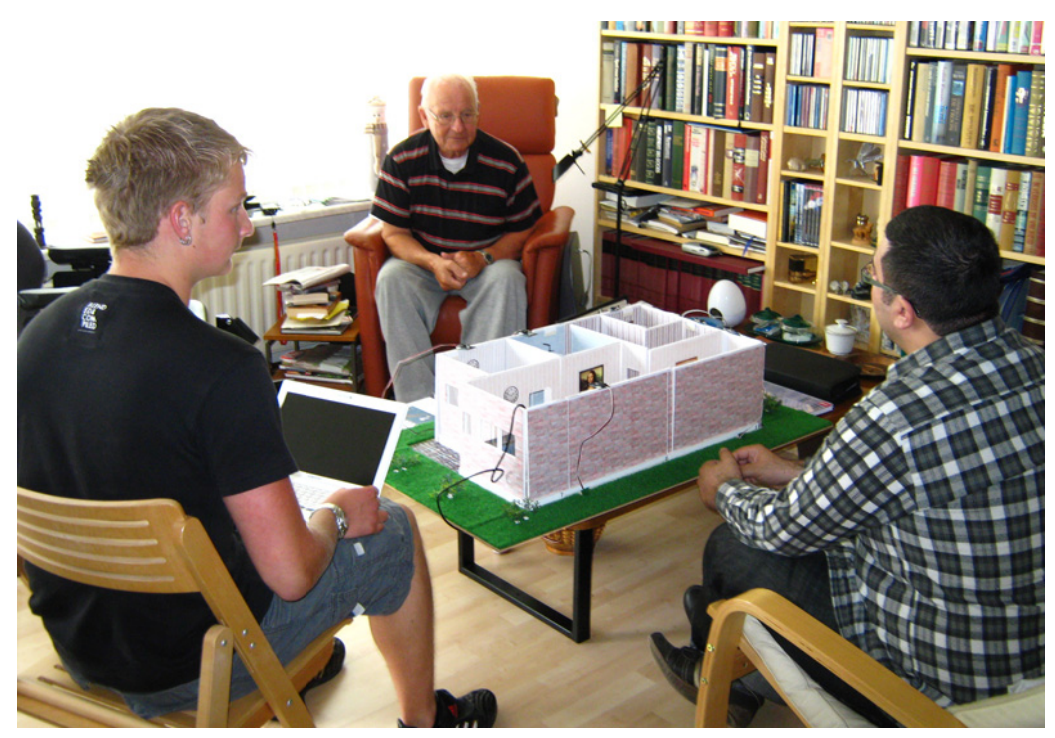

Fig. 2. In the Senior-Create IT project, the students used a mock-up for co-design

\subsection{Interactive Wall in Psychogeriatric Ward of Nursing Home}

A group of three students from the program 'Ambient Interaction' was asked to work on an assignment in nursing home Naarderheem, where approximately 60 elderly with severe dementia live in a psychogeriatric ward. People suffering from dementia often have a problem with way finding and are being restless. The students were asked to make an interactive installation for reducing the amount of wandering of the inhabitants of the ward. The interactive wall aims at making these people feel more at home in the nursing homes by guiding them with a motion triggered audio path and showing them images and short movie tracks from their hometown on large windows. The students started with observational studies in the nursing home and a literature study. Following on from this, they created some prototypes that were discussed with the caregivers. The head of the nursing home allocated a budget for building an interactive wall that was built by the students. After finalization of the wall, the students carried out an observational study, of which the results show that the interactive wall succeeds in attracting people and thus reducing the wandering behaviour. Remarks of the elderly as well as the family and caretakers support this conclusion.

\section{Lessons Learned}

During the five years that we adopted the Living Lab methodology and worked with students, we experienced a number of findings that relate to either the methodology or working with students. These are collated in the following lessons: 
Engage the Stakeholders. The involvement of different stakeholders is of particular importance in a Living Lab to secure the development of usable and useful products and services, as also pointed out by [8]. In the BiebBeep project the involvement of for example the library staff was seen as very valuable, for example in stimulating interesting content. With regard to the Health-lab projects, all stakeholders (elderly, staff, management) were involved to enable the successful realization of the projects. Regular meetings with all stakeholders are needed to discuss progress and give feedback. However, in other projects not described here the role of the stakeholders was less positive. Some tended to modify the targets during the project, in some cases the hard- or software was not available in time and some stakeholders we just very slow in responding, with as a result too much delay in the project.

Take Care of Sufficient Technical Support. In many projects, the applications or services need to be tested for more than six months. During such a long period, many technical issues may arise, such as batteries that get empty, hard disks that crash or cleaners that pull out the plug of the router.. It is advised to have a watchdog function installed on the systems and still consider the maintenance, which is likely to cost a lot of effort.

Improve the Student's Skillset. In all of the projects, the students had to carry out user studies. We found that students differed very much in their communication skills, and often lacked basic research skills. Therefore, students are likely to need an intensive training and guidance before and during participating.

Embedding in the School Calendar. At the HvA, the student projects last 20 weeks and start either in September or February. This means that the infrastructure and all stakeholders need to be ready to start the projects at that particular time. Furthermore, 20 weeks is often too short for students to participate in the entire cycle of problem > research question >prototype building >user evaluation.

Evaluation of the Student Work. Teachers needed different evaluation methods as they found it difficult to evaluate the (inter-disciplinary) group achievements of students in the research projects, as it differs from the regular projects at HvA computer science, that are usually focussed on product building.

Students Learn to do Research Hands on. The positive aspects of getting students to do research in the wild is that students are actively made aware of the various realworld aspects of doing research. In the Health-lab, for example, the ethical part of doing research on monitoring systems was highlighted.

Use Multidisciplinary Groups. In the Health-lab projects, the students involved came from from different disciplines, such as occupational therapy and communication and media design. Such interdisciplinary approach needs some extra support (from the supervisors) in the beginning, but gave more thoughtful results from a broader perspective in the end. 


\section{Conclusion}

This paper presented a myriad of projects to exemplify and explain how living labs can be used and employed in education settings, such as done at the Amsterdam University of Applied Sciences. The lessons learned that are presented in this paper increase the understanding of how Living Labs can be used for educational purposes, but also for ICT innovation and development.

Acknowledgments. The research reported in this paper has been supported by the Foundation Innovation Alliance (SIA) with funding from the Dutch Ministry of Education, Culture and Science (OCW), as part of the 'Smart Systems for Smart Services' and 'SpaceSee' projects, and via the 'Pieken in de Delta' program by the Ministry of Economic Affairs as part of the 'Health-lab' project.

\section{References}

[1] Abowd, G.D., Bobick, A.F., Essa, I.A., Mynatt, E.D., Rogers, W.A.: The aware home: A living laboratory for technologies for successful aging. In: Proceedings of the AAAI 2002 Workshop Automation as Caregiver, pp. 1-7 (2002)

[2] Alizadeh, S., Bakkes, S., Kanis, M., Rijken, M., Kröse, B.: Telemonitoring for assisted living residences: The medical specialists' view. In: Jordanova, M., Lievens, F. (eds.), In Proceedings of the Med-e-Tel 2011; The International eHealth, Telemedicine and Health ICT Forum for Educational, Networking and Business, pp. 75-78 (2011)

[3] Casey, M.E., Savastinuk, L.C.: Library 2.0-service for the next-generation library. Library Journal 131(14), 40-43 (2006)

[4] Følstad, A.: Living labs for innovation and development of information and communication technology: a literature review. The Electronic Journal for Virtual Organizations and Networks 10, 99-131 (2008)

[5] Kanis, M., Alizadeh, S., Groen, J., Khalili, M., Robben, S., Bakkes, S., Kröse, B.: Ambient Monitoring from an Elderly-Centred Design Perspective: What, Who and How. In: Keyson, D.V., Maher, M.L., Streitz, N., Cheok, A., Augusto, J.C., Wichert, R., Englebienne, G., Aghajan, H., Kröse, B.J.A. (eds.) AmI 2011. LNCS, vol. 7040, pp. 330-334. Springer, Heidelberg (2011)

[6] Markopoulos, P.: Towards a living lab research facility and a ubiquitous computing research programme. In: The CHI2001 workshop Distributed and Disappearing UI's in Ubiquitous Computing. Citeseer (2001)

[7] Schumacher, J., Niitamo, V.P., Vorarlberg, F.: European living labs: A new approach for human centric regional innovation. wvb, Wiss. Verl. (2008)

[8] Svensson, J., Ihlström Eriksson, C., Ebbesson, E., Åkesson, M.: Methods and techniques for user contribution: Challenges from a living lab perspective (2009)

[9] van Kasteren, T.L.M., Englebienne, G., Kröse, B.J.A.: Activity recognition using semiMarkov models on real world smart home datasets. J. Ambient Intell. Smart Environ. 2(3), 311-325 (2010) 